
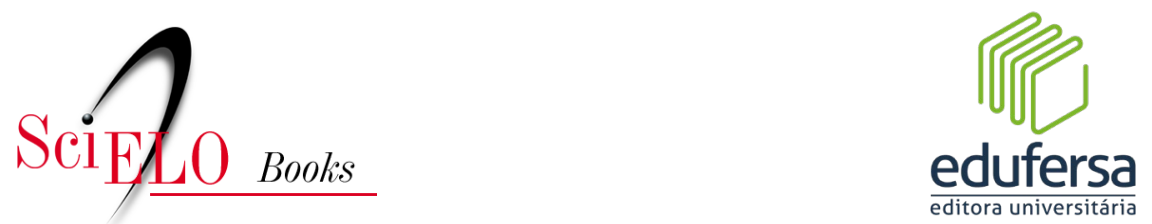

\title{
Capítulo 6 - Relação entre a motivação para empreender dos empreendedores aracatienses e suas ações para o desenvolvimento da economia local
}

\author{
Sophia Caroline da Costa Soares \\ Suely Xavier dos Santos \\ Agostinha Mafalda Barra de Oliveira
}

\section{SciELO Books / SciELO Livros / SciELO Libros}

SOARES, S. C. C., SANTOS, S. X., and OLIVEIRA, A. M. B. Relação entre a motivação para empreender dos empreendedores aracatienses e suas ações para o desenvolvimento da economia local. In: OLIVEIRA, A. M. B., ed. Empreendedorismo: registros de estudos teórico-empíricos no semiárido [online]. Mossoró:

EdUFERSA, 2018, pp. 181-213. ISBN: 978-85-5757-090-0. https://doi.org/10.7476/9786587108667.0008.

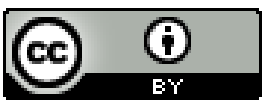

All the contents of this work, except where otherwise noted, is licensed under a Creative Commons Attribution 4.0 International license.

Todo o conteúdo deste trabalho, exceto quando houver ressalva, é publicado sob a licença Creative Commons Atribição 4.0. 


\title{
RELAÇÃO ENTRE A MOTIVAÇÃO PARA EMPREENDER DOS EMPREENDEDORES ARACATIENSES E SUAS AÇÕES PARA O DESENVOLVIMENTO DA ECONOMIA LOCAL
}

\author{
Sophia Caroline da Costa Soares \\ Suely Xavier dos Santos \\ Agostinha Mafalda Barra de Oliveira
}

\subsection{Introdução}

O empreendedorismo ganha cada vez mais destaque no âmbito mundial. Por isso, apresenta-se como um fator fundamental para aquecer o mercado e gerar, com isso, negócios que buscam criar e melhorar produtos e/ou serviços para atender a necessidades, bem como propiciar mais emprego e renda. Como afirma Dornelas (2001, p. 24), “[...] o empreendedorismo é o combustível para o crescimento econômico, criando emprego e prosperidade".

Nesse contexto, estudos têm sido desenvolvidos para mensurar os impactos causados pelo empreendedorismo no desenvolvimento econômico. Um deles é a pesquisa anual do Global Enterpreneurship Monitor (GEM). Essa pesquisa foi realizada, pela primeira vez, em 1999, com a participação de 10 países. Desde então, já obteve a participação de quase 100 países, em momentos diferentes. Em 2015, contou com a participação de 60 países (GEM, 2015). Acredita-se que isso se deva ao fato de que essa pesquisa vem sendo considerada a maior sobre empreendedorismo, em nível mundial, com o objetivo de entender a função deste no desenvolvimento econômico dos países participantes. 
O GEM (2010) classifica o empreendedorismo, quanto à motivação para empreender, em: empreendedorismo por necessidade e empreendedorismo por oportunidade, e defende que o empreendedorismo por oportunidade contribui mais para o desenvolvimento econômico de um país. No entanto, não há estudos empíricos alheios ao GEM que comprovem essa premissa. Por isso, faz-se necessário um estudo visando comprovar se o empreendedorismo por oportunidade tem uma contribuição maior para o desenvolvimento econômico de uma localidade que o empreendedorismo por necessidade.

Pelo exposto, este trabalho pretende realizar tal comprovação no município de Aracati. Essa escolha deveu-se à importância que o município, com aproximadamente 72 mil habitantes, teve e ainda tem no cenário econômico e social do estado e do país. O município de Aracati, região Leste do Estado do Ceará, está localizado a aproximadamente $150 \mathrm{~km}$ da capital Fortaleza e possui uma população de 72.248 pessoas (INSTITUTO BRASILEIRO DE GEOGRAFIA E ESTATÍSTICA [IBGE] CIDADES, 2014). Sua base econômica é situada nas atividades comerciais e industriais, tendo a pesca de crustáceos, o turismo receptivo, o cultivo de algumas frutas, como o caju e melão, e a extração petrolífera como principais destaques para o desenvolvimento econômico da cidade (ARACATINET, 2009). A cidade também é bastante conhecida pelas belezas de suas praias, como Canoa Quebrada e Majorlândia, que recebem milhares de turistas em várias épocas do ano, bem como pelo histórico arquitetônico presente nos azulejos dos casarões e em suas igrejas barrocas.

Para tanto, estabelece-se, como objetivo geral deste trabalho, analisar a relação entre a motivação para empreender dos empreendedores aracatienses e suas ações para o desenvolvimento da economia local. E, como objetivos específicos: classificar os empreendedores, em relação a sua motivação para empreender, em por oportunidade ou por necessidade; verificar as ações desenvolvidas e pretendidas de cada 
empreendedor, que contribuem para o desenvolvimento da economia local; verificar se há diferenças significativas entre as ações desenvolvidas pelos empreendedores por oportunidade e os empreendedores por necessidade.

Nos dois tópicos seguintes, será apresentada uma breve explanação sobre a relação do empreendedorismo com o desenvolvimento econômico de um país e um detalhamento em relação à classificação da motivação para empreender do GEM, seguidos dos tópicos de procedimentos metodológicos, apresentação e análise dos dados e considerações finais.

\subsection{Importância do empreendedorismo para o desenvolvimento da economia}

O empreendedorismo vem desempenhando um papel de relevância para o progresso econômico. Isso se deve à ação do agente do empreendedorismo, o empreendedor. A contribuição do empreendedor é pautada pela concorrência estabelecida no mercado e pela inovação. Schumpeter (1983) argumenta que o empreendedor, indivíduo responsável pelo processo de destruição criativa, é quem impulsiona e aquece o chamado capitalismo, por meio da criação de novos produtos/serviços, novas técnicas de produção e de distribuição, que são utilizados como uma forma de excluir os métodos ineficientes tanto em relação ao tempo quanto ao custo.

Nesse sentido, é notório que o empreendedorismo vem desempenhando um papel de destaque no aquecimento econômico, como gerador de emprego e renda e de inovação contínua para o mercado. Como afirma Drucker (2005), o empreendedorismo é um fenômeno cultural, econômico e tecnológico. Sendo assim, é o impulsionador da economia, pois gera emprego e renda, ajuda a desenvolver pesquisas e estimula o desenvolvimento nos âmbitos local e nacional. 
Em termos mais operacionais, de acordo com o GEM (2015, p. 7), empreendedorismo refere-se a: “[...] qualquer tentativa de criação de um novo empreendimento, como, por exemplo, uma atividade autônoma, uma nova empresa ou a expansão de um empreendimento existente."

$\mathrm{Na}$ área de pesquisa, o empreendedorismo surge como estímulo para docentes e discentes de instituições de ensino, especialmente as de nível superior, desenvolverem pesquisas sobre a cultura empreendedora, sobre as necessidades dos próprios empreendedores e sobre a contribuição das ações do empreendedorismo para o crescimento econômico do país. Assim, o empreendedorismo é o fomento para a criação de empresas inovadoras de cunho tecnológico (incubadoras e parques), para a realização de estudos viáveis à sociedade e para a construção de projetos que promovem o desenvolvimento do mercado de risco.

Com o grande número de empresas que vem surgindo, é imprescindível oferecer, além de qualidade, um produto inovador, que surpreenda e deixe satisfeito o consumidor para agregar valor e diminuir a paridade entre as empresas. Dessa maneira, a inovação tecnológica vem se destacando por estar diretamente relacionada com o empreendedorismo no desenvolvimento econômico.

Nesse ambiente de inovação tecnológica, as pequenas e médias empresas (PMEs) se destacam, passando a oferecer o maior número de empregos e a concorrerem no mercado local, no nacional e, até mesmo, no internacional (DOLABELA, 1999). Assim, o empreendedorismo assume o papel de captar os recursos disponíveis para o desenvolvimento e utilizá-los de forma eficiente para gerar valor. Dessa forma, o empreendedorismo age tanto no desenvolvimento local, em nível regional, quanto em nível nacional.

Segundo Dornelas (2001, p. 40), o desenvolvimento econômico "[...] é dependente de quatro fatores críticos, que devem ser analisados, para então se entender o processo empreendedor". Os quatro 
fatores críticos para o autor seriam o talento, a tecnologia, o capital e o know-how, elementos fundamentais para empreender e obter um negócio de sucesso.

O talento diz respeito às características empreendedoras presentes no indivíduo, como percepção, senso de direção, dedicação, espírito inovador e as habilidades/competências para lidar com as adversidades que o negócio irá proporcionar. Juntamente com o talento, a tecnologia apresenta um papel importante para que o processo empreendedor possa acontecer.

A tecnologia, que é o conjunto de técnicas, instrumentos, métodos, tem como objetivo solucionar um problema, apresentando um papel fundamental no âmbito da inovação. Fomentar a tecnologia no processo empreendedor possibilita ao negócio conquistar um diferencial para produzir produtos/serviços com maior qualidade. Porém, para que esses recursos possam ser explorados e revertidos em ações benéficas ao negócio, faz-se necessário possuir um capital apropriado. Isso porque o capital será o combustível para que tudo o que foi planejado possa ser concretizado.

Outro fator de grande importância para o processo empreendedor é o know-how. Essa expressão inglesa diz respeito à junção de todos os conhecimentos (técnicas, habilidades, informações) que venham agregar valor ao negócio e trazer vantagem competitiva (DORNELAS, 2012).

Contudo, para avaliar o impacto que o empreendedorismo acarreta no crescimento econômico, é indispensável considerar e identificar a motivação para empreender. Devido a sua importância, em especial para este estudo, o tópico seguinte será destinado a tratar sobre a classificação do empreendedorismo quanto à motivação para empreender. 


\subsection{Classificação do empreendedorismo quanto à motivação para empreender}

De acordo com o GEM (2010), o empreendedorismo, quanto à motivação, pode ser classificado em dois tipos: empreendedorismo por necessidade e empreendedorismo por oportunidade. Essa foi a classificação utilizada neste trabalho. Pelo exposto, os subtópicos seguintes detalham as características particulares desses dois tipos de empreendedorismo.

\subsubsection{Empreendedorismo por necessidade}

O empreendedorismo por necessidade se dá por falta de opção de emprego, não é baseado na identificação de novas chances, de ideias inovadoras que possibilitem negócios diferenciados. Essa forma de empreender está muito ligada à falta de emprego e renda, sendo constatado que, no momento em que a oferta de trabalho aumenta, o empreendedorismo por necessidade tende a diminuir (GEM, 2010). Dessa forma, os agentes desse empreendedorismo, os empreendedores por necessidade, são "[...] aqueles que iniciam um empreendimento autônomo por não possuírem melhores opções para o trabalho e então abrem um negócio a fim de gerar renda para si e suas famílias.” (GEM 2011, p. 47).

O agente do empreendedorismo por necessidade é motivado, não pela identificação de oportunidade, mas sim pela necessidade de sobreviver. Por esse motivo, acaba desenvolvendo a atividade empreendedora de forma não planejada e sem grandes perspectivas. Para Dornelas (2012, p. 13), no empreendedorismo por necessidade,

[...] o candidato a empreendedor se aventura na jornada empreendedora mais por falta de opção, por estar desempregado e não ter alternativas de trabalho. Nesse caso, esses negócios costumam ser criados informalmente, não são planejados de forma adequada e 
muitos fracassam bastante rápido, não gerando desenvolvimento econômico e agravando as estatísticas de criação e mortalidade dos negócios.

Mendes aponta que (2009, p. 10), “[...] os empreendedores por necessidade oscilam entre a vontade de vencer e a vontade de voltar ao mercado de trabalho formal". Lemes Júnior e Pisa (2010) complementam que os empreendedores por necessidade geralmente iniciam seu negócio de maneira informal.

Degen (2009) defende que, nos negócios iniciados por necessidade, o empreendedor tende a trabalhar bem mais e ganhar menos que se estivesse em um emprego. Por esse motivo, só recorre ao empreendedorismo por necessidade e ao auto emprego como uma opção de sobrevivência, quando não há habilidades nem competências para desempenhar um trabalho na forma de emprego formal. Prova disso é que muitos deles, na primeira oportunidade de se inserir no trabalho formal ou retornar a ele, não pensam duas vezes para liquidar o seu negócio.

Em consequência, os negócios que começam motivados pela necessidade podem ser classificados como medíocres. Geralmente, esses negócios são considerados medíocres, porque apresentam uma baixa lucratividade, bem como um crescimento restrito. São negócios que não apresentam dificuldade para serem montados por qualquer empreendedor e que nascem do excesso de demanda do mercado. No entanto, precisam lidar com os riscos provindos do negócio, principalmente devido à concorrência acirrada. Isso, por sua vez, faz com que esse tipo de empreendedorismo cause pouco impacto no crescimento econômico de um país. Além disso, devido à criação de negócios sem inovação e com pouco ou nenhum recurso tecnológico, os empreendimentos iniciados por necessidade não oferecem uma boa perspectiva de geração de emprego e renda. 
Dornelas (2012) e Lemes Júnior e Pisa (2010) afirmam que o empreendedorismo por necessidade é predominante em países em desenvolvimento. Tal afirmação se deve ao cenário de desemprego, à falta de incentivos e de condições favoráveis para desenvolver a atividade empreendedora, à ausência de qualificação dos empreendedores para gerenciarem o negócio, bem como às limitações para inserção no mercado de trabalho formal.

Em um cenário econômico caracterizado por um índice crescente de desemprego estrutural, é notória a presença do empreendedorismo por necessidade. Nesse sentido, Degen (2008, p. 17) enfatiza que “[...] uma maior atividade empreendedora por necessidade geralmente reflete uma situação de estagnação ou crise econômica no país, a falta de empregos ou mesmo a redução de empregos força as pessoas a empreender para sobreviver".

Castelo Branco e Schneider (2012, p. 29) ainda acrescentam que o empreendedorismo por necessidade "[...] é um tipo de empreendedorismo com maior probabilidade de insucesso e que se mostra mais presente em sociedades com maior desequilíbrio econômico e social". Ou seja, à proporção que a economia, bem como a sociedade do país entram em um estado de crescimento compensado, esse tipo de empreendedorismo começa a ficar menos evidente.

No entanto, também é importante ressaltar outros fatores que geram ou impedem a atividade empreendedora em um país. Degen (2008, p. 17) aponta que os fatores que inibem o desenvolvimento do empreendedorismo são

[...] a educação e o treinamento da população, o número e a qualidade dos centros de pesquisa e de tecnologia, a disponibilidade de capital de risco, a profundidade do mercado, a existência de uma infraestrutura adequada e uma legislação que facilite atividade empreendedora. 
Ao analisar o empreendedor por necessidade de acordo com os cinco fatores motivacionais desenvolvidos por Naffziger, Hornsby e Kuratko (1994), é perceptível a ineficiência para desenvolver a atividade empreendedora. $\mathrm{O}$ empreendedor por necessidade não está disposto a correr riscos nem apresenta características que o auxiliem na gestão e no crescimento do negócio. $\mathrm{O}$ indivíduo não empreende por influência de terceiros, não esquematiza metas para ampliação do negócio, muito menos avalia as influências que poderão afetar o negócio, pois a necessidade de sobrevivência é a sua motivação. Assim, nota-se que o empreendedorismo por necessidade é feito de forma rápida e sem preparo, pois não há preocupação para realizar um planejamento ou estudo sobre o negócio.

Pelo exposto, de acordo com o GEM (2010), o empreendedorismo por necessidade não é considerado o mais relevante para o crescimento econômico de um país. Isso é devido à falta de inovação e de recursos tecnológicos mais marcantes nos negócios dessa natureza, o que caracteriza um atraso no desenvolvimento, tanto no aspecto econômico quanto no social, gerando altos índices de atividade informal e de mortalidade de empresas.

\subsubsection{Empreendedorismo por oportunidade}

Por outro lado, empreendedorismo por oportunidade ocorre quando, mesmo havendo uma opção de trabalho, existe o desejo de investir em uma ideia inovadora com o objetivo de independência pessoal e financeira, além da necessidade de realização e de autonomia. Assim, os empreendedores por oportunidade são aqueles que " [...] optam por iniciar um novo negócio, mesmo quando possuem alternativas de emprego e renda, ou ainda, para manter ou aumentar sua renda pelo desejo de independência no trabalho." (GEM 2011, p. 47). 
Esse tipo de empreendedorismo atende à visão de empreendedorismo como um processo. Assim, as fases do processo empreendedor são: o reconhecimento de uma oportunidade, a decisão de ir em frente e reunir os recursos iniciais, o lançamento do novo empreendimento, a construção do sucesso e a coleta das recompensas. Essas fases do processo empreendedor se desenvolvem continuamente ao longo do tempo, estando todas interligadas (BARON; SHANE, 2007).

Ao considerar a primeira fase do processo de empreender como o reconhecimento de uma oportunidade para criar algo novo é que a atividade vem ganhando maior relevância no mercado e cada vez mais adeptos, sejam práticos ou estudiosos sobre ela. Dolabela (1999, p. 87) acrescenta que a oportunidade

[...] tem algo novo e atende a uma demanda dos clientes, representando um nicho de mercado. Ela é atrativa, ou seja, tem potencial para gerar lucros, surge em um momento adequado em relação a quem irá aproveitá-la - o que a torna pessoal - é durável e baseia-se em necessidades insatisfeitas.

Segundo Baron e Shane (2007), os estudos respaldados nos princípios de Schumpeter identificaram três fontes de oportunidade, denominadas de: mudança tecnológica, mudança política ou de regulamentos e mudança social e demográfica.

A mudança tecnológica é uma fonte de oportunidade, pois possibilita que pessoas façam algo de forma mais inovadora e eficiente. Por sua vez, as mudanças políticas ou de regulamentação possibilitam a concepção de ideias a serem utilizadas para remanejar os recursos de maneira inovadora, visando distribuir as riquezas de uma pessoa para outra. Importante ressaltar que nem sempre esse tipo de mudança incrementa a produtividade, gerando apenas o lucro à custa dos outros. As mudanças sociais e demográficas são importantes minas de oportunidades de empreendedorismo. Isso ocorre por possibilitarem 
a alteração da demanda por produtos e serviços e por proporcionarem igualmente soluções para as necessidades dos clientes (BARON; SHANE, 2007).

Assim, pode-se dizer que aquilo que tem uma utilidade ou que atende a uma necessidade pode tornar-se uma oportunidade. Portanto, é importante partir da premissa de que as oportunidades são, por sua vez, advindas das necessidades humanas. Essas necessidades podem ser do próprio empreendedor ou de outros que estão a sua volta. Assim, conhecendo bem essas necessidades, será possível localizar lacunas, nichos e focos pouco descobertos (CASTELO BRANCO; SCHNEIDER, 2012).

Dessa forma, o empreendedorismo por oportunidade é a vontade de valer-se de uma oportunidade existente no mercado por meio da concepção de um negócio. Assim diferentemente do empreendedorismo por necessidade, que demanda imediatismo, o empreendedorismo por oportunidade preza pela análise da ideia e do ambiente, pelo planejamento das estratégias. Após esse processo, o empreendedor busca a inovação para conseguir um diferencial e assim alcançar seu objetivo, que é gerar emprego e renda (LEMES JÚNIOR; PISA, 2010). Nessa perspectiva, Filion (1999, p. 19) afirma que

[...] o empreendedor caracteriza-se por ser uma pessoa criativa, marcada pela capacidade de estabelecer e atingir objetivos e que mantém alto nível de consciência do ambiente em que vive, usando-a para detectar oportunidades de negócios. Um empreendedor que continua a aprender a respeito de possíveis oportunidades de negócios e a tomar decisões moderadamente arriscadas que objetivam a inovação, continuará a desempenhar um papel empreendedor.

Para Degen (2008), o empreendedorismo motivado por oportunidade consegue gerar um maior impacto no crescimento econômico de um país. Isso porque os empreendedores estão mais bem preparados, 
desenvolvem seus negócios utilizando inovações e tecnologias recentes. Assim, muitos desses negócios apresentam um potencial elevado do que o autor denomina de "crescimento sustentado". Dessa maneira, esse tipo de empreendedorismo consegue gerar maiores índices de emprego e riqueza.

Para Castelo Branco e Schneider (2012), o empreendedorismo por oportunidade é respaldado na análise do ensejo, de modo que as decisões são mais planejadas, influenciadas pela razão e pela vontade de empreender. Portanto, nesse tipo de empreendedorismo, são realizados estudos de mercado, análise de tendências, de demandas, para detectar as oportunidades.

Outro aspecto importante é que, diferentemente do empreendedorismo por necessidade, esse tipo de empreendedorismo está mais presente nos países desenvolvidos. Para entender como o empreendedorismo pode influenciar e afetar o desenvolvimento econômico de um país e ser até mesmo predominante em países desenvolvidos, Sarfati (2013) enumera três estágios de desenvolvimento econômico: o estágio movido por fatores de produção, o estágio movido pela eficiência e o estágio movido pela inovação.

No estágio movido pelos fatores de produção, são encontradas as atividades com baixos índices de desenvolvimento econômico, presentes no setor agrícola e nos chamados empreendedores "estilo de vida”, que são as pessoas que empreendem para suprir a necessidade. Já no estágio de eficiência, há predominância na produção de mercadorias tendo um baixo número de empresas prestadoras de serviço. Assim, esse estágio é marcado pela industrialização e pela busca de fazer (produzir) mais com menos (recursos). E, no estágio movido pela inovação, prevalecem as atividades pautadas no conhecimento e na informação voltadas para a qualidade de produtos e serviços, sendo sinônimas do empreendedorismo (SARFATI, 2013). De acordo com tais considerações, é notório que o empreendedorismo tem um papel fundamental na economia 
de países movidos pela inovação (desenvolvidos), pois as atividades são pautadas no desenvolvimento pessoal, de serviços e de educação.

Considerando a perspectiva da realidade nacional, os resultados obtidos pelo GEM (2013) demonstraram que o empreendedorismo vem crescendo ano após ano, tanto quantitativamente quanto qualitativamente. Em 2002, primeiro ano em que o Brasil participou da pesquisa, a taxa de empreendedorismo por oportunidade não chegava a 43\%; já em 2013, onze anos depois, a proporção de empreendedores por oportunidade no país foi de $71,3 \%$. Os resultados de 2013 demonstraram que a relação oportunidade/necessidade no Brasil era de 2,5, ou seja, dentre os empreendedores iniciais, existiam 2,5 que começaram um negócio por terem identificado uma oportunidade para cada empreendedor por necessidade. Tal constatação “[...] indica a vitalidade dessa atividade no Brasil, onde o empreendedorismo por oportunidade continua sendo uma alternativa para milhões de brasileiros" (GEM, 2013).

Tendo como base sua pesquisa e os estudos do GEM (2010; 2011), Dornelas (2012) também argumenta que, no empreendedorismo por oportunidade, o empreendedor tem definido um objetivo. $\mathrm{O}$ empreendedor cria o negócio sabendo aonde deseja chegar, possuindo uma visão de futuro, utilizando-se do planejamento estratégico para conseguir gerar mais lucro e serviço.

\subsection{Procedimentos metodológicos}

Para alcançar o objetivo proposto, a entrevista semiestruturada foi utilizada como instrumento de coleta para o referido trabalho. Para tanto, o roteiro de entrevista foi estruturado em duas partes. Na primeira parte, foram colhidas informações sobre os dados pessoais do empreendedor e do empreendimento, tais como sexo (feminino/ masculino), idade, nível de escolaridade, atividade desenvolvida pela empresa (comércio, serviço ou indústria). A segunda parte continha 14 
questões estruturadas a fim de obter as respostas dos empreendedores conforme os objetivos específicos deste trabalho. O roteiro de entrevista encontra-se no Apêndice deste trabalho.

Para realizar o estudo, foram contatados 20 microempreendedores individuais (MEIs) da cidade, cadastrados no Serviço Brasileiro de Apoio às Micro e Pequenas Empresas (Sebrae), para explicar o estudo e sua relevância, bem com solicitar-lhes a participação. Apesar do número crescente de microempreendedores individuais no município de Aracati, a entrevista foi realizada apenas com seis indivíduos. Isso se deveu à indisponibilidade de tempo da maioria dos empreendedores para participarem do estudo.

Dessa forma, a pesquisa do presente trabalho foi desenvolvida com seis MEIs locais, sendo quatro MEIs com empreendimentos no comércio, um na indústria e mais um na prestação de serviços. Todos esses empreendimentos possuem dois anos ou mais de abertura. Dentre os MEIs, três são do sexo masculino e três são do sexo feminino, com idade entre 20 e 50 anos. Dos seis entrevistados, um possui o ensino fundamental incompleto, dois possuem o ensino médio completo, um é graduado em Letras, um está cursando Administração e o outro Recursos Humanos. Por uma questão de praticidade e melhor entendimento, cada entrevistado será tratado pela letra $\mathrm{E}$, que remete a empreendedor, seguido de um número que vai de 1 a 6 .

O E1 é do sexo masculino, tem 43 anos, possui o ensino médio completo e trabalha na área de comércio de artigos de caça, pesca e camping. Com quatro anos de empresa legalizada, o E1 tem, como público-alvo, agricultores da região, uma clientela razoável, porém fiel. O estabelecimento é próprio e está localizado no centro da cidade, porém o espaço é pequeno para acomodar os inúmeros produtos.

O E2 é do sexo feminino, tem 34 anos, possui graduação em Letras e trabalha na área de comércio de vestuário e acessórios. A empresa tem dois anos de legalização, o estabelecimento é alugado, com um 
espaço agradável e organizado para atender ao público feminino de todas as idades.

O E3 é do sexo masculino, tem 21 anos, está cursando o ensino superior em Recursos Humanos e trabalha na área de comércio de alimentos (lanchonete). Com um ano e nove meses de empresa legalizada, o estabelecimento élocalizado na residência do empreendedor, não conta com uma estrutura organizada e atende apenas às pessoas do bairro.

O E4 é do sexo masculino, tem 30 anos, está cursando o ensino superior em Administração e trabalha na área de comércio de artigos de cama, mesa e banho e peças decorativas para o lar. A empresa tem três anos e meio, está localizada em um ponto central da cidade, com um espaço bem estruturado, planejado para atender a todos os clientes com conforto e segurança.

O E5 é do sexo feminino, tem 47 anos, possui apenas o ensino fundamental incompleto e trabalha na área de prestação de serviço, como costureira. A empresa está legalizada há quatro anos e funciona na residência da empreendedora, atendendo ao público em geral.

O E6 é do sexo feminino, tem 38 anos, possui o ensino médio completo e trabalha na área da indústria, com a fabricação de peças artesanais. A empresa está funcionando há dois anos e três meses em um centro de artesanato, com um espaço reduzido, porém suficiente para atender aos clientes e expor, de forma satisfatória, as peças produzidas. As informações até agora explanadas estão resumidas no Quadro 5: 
Quadro 5 - Caracterização dos sujeitos de pesquisa

\begin{tabular}{|c|c|c|c|c|}
\hline Entrevistado & Sexo & Idade & Escolaridade & $\begin{array}{c}\text { Atividade } \\
\text { desenvolvida }\end{array}$ \\
\hline E1 & Masculino & 43 & Ensino médio completo & Comércio \\
\hline E2 & Feminino & 34 & $\begin{array}{c}\text { Ensino superior } \\
\text { completo }\end{array}$ & Comércio \\
\hline E3 & Masculino & 21 & $\begin{array}{c}\text { Ensino superior em } \\
\text { andamento }\end{array}$ & Comércio \\
\hline E4 & Masculino & 30 & $\begin{array}{c}\text { Ensino superior em } \\
\text { andamento }\end{array}$ & Comércio \\
\hline E5 & Feminino & 47 & $\begin{array}{c}\text { Ensino fundamental } \\
\text { completo }\end{array}$ & Serviço \\
\hline E6 & Feminino & 38 & $\begin{array}{c}\text { Ensino médio completo } \\
\text { Indústria/ } \\
\text { Comércio }\end{array}$ \\
\hline
\end{tabular}

Fonte: Elaboração própria (2015).

$\mathrm{Na}$ ocasião do primeiro contato, as entrevistas foram agendadas com os seis que se dispuseram a participar. Tais entrevistas foram realizadas com, no máximo, duas semanas após o primeiro contato, no final do mês de julho de 2015, nos respectivos empreendimentos dos empreendedores. E1 e E6 preferiram que acontecesse durante a manhã, pois seria mais tranquilo e não haveria interrupções. Embora E1 tenha escolhido o período da manhã pela tranquilidade no comércio, a entrevista ainda foi interrompida por duas vezes, pois havia clientes no empreendimento e não havia funcionário para atendê-los. Já os outros quatro empreendedores escolheram o período da tarde. As entrevistas tiveram uma duração entre 47 e 118 minutos. Apenas E4 estava acompanhado por uma pessoa da família, mas que não interferiu na entrevista. Os demais estavam sozinhos.

Para atingir os objetivos pretendidos, a pesquisa foi do tipo qualitativa. Na pesquisa qualitativa, o conhecimento revela-se mediante os aspectos relacionados à condição do sujeito. Minayo (1996, p. 10) conceitua o método qualitativo como "[...] aquele capaz de incorporar a questão do significado e da intencionalidade como inerentes aos 
atos, às relações, e às estruturas sociais, sendo essas últimas tomadas tanto no seu advento quanto na sua transformação, como construções humanas significativas".

Para o tratamento dos dados, recorreu-se a uma técnica chamada de "análise de conteúdo", sugerida por Bardin (1979, pg. 31), que a define como

[...] um conjunto de técnicas de análise das comunicações visando obter, através de procedimentos sistemáticos e objetivos de descrição do conteúdo das mensagens, indicadores (quantitativos ou não) que permitam inferir conhecimentos relativos às condições de produção/recepção (variáveis inferidas) dessas mensagens.

\subsection{Apresentação e análise dos dados}

A motivação para empreender por necessidade predomina em E3 e E5, visto que os respondentes afirmam que só resolveram criar a empresa por não terem uma opção de trabalho, como fica evidente na fala de E3 (2015): "O que me fez abrir a lanchonete foi a necessidade de poder me sustentar. Isso porque tinha acabado o ensino médio e não tinha condições de me manter". Da mesma maneira, é evidente na fala de E5 (2015):

[...] estudei pouco, me casei cedo, tive meus filhos... [pausa]. Por não ter estudo, não consegui um trabalho "direitinho", que ajudasse nas contas. Daí, como sempre costurei e tinha que ajudar meu marido nas contas e criar meus meninos, uni as duas coisas. Depois de uns anos, com os filhos já maiores, foi que eles resolveram abrir essa empresa.

Ao falar sobre a volta ao trabalho formal, é notória a vontade de E3 em ingressar no mercado de trabalho formal: “[...] assim que conseguir 
esse emprego, eu fecho a lanchonete e pronto. Quero estabilidade, um porto-seguro, me firmar, estabelecer. E pra eu conseguir isso, só com um trabalho, é lógico!". Já E5 (2015) reflete que, se estivesse em um emprego formal, poderia estar ganhando mais. No entanto, devido à idade e à falta de estudos, acaba se contentando com a situação atual, como é perceptível nesta sua fala: "Num sei... [pausa para refletir] se eu tivesse estudado mais, acho que podia até ganhar um 'dinheirinho' a mais, mas não deu. Mas tá bom assim mesmo, as costuras tão aumentando”.

Os empreendedores E3 e E5 demonstram empreenderem por necessidade devido a problemas financeiros e por não terem opções melhores de emprego, o que vai ao encontro do ponto de vista de Dornelas (2012) e do GEM (2011). Dornelas (2012) defende que o indivíduo que se lança na jornada empreendedora por falta de alternativa e/ ou pelo desemprego é um empreendedor por necessidade. Também existem evidências, no discurso desses entrevistados, de disputa entre a vontade de crescer e a de ingressar no mercado formal (MENDES, 2009). Outra característica perceptível na fala de E5 e que representa o empreendedorismo por necessidade é a deficiência da educação e do treinamento da população, que acaba inibindo o desenvolvimento das características empreendedoras (DEGEN, 2008).

Além disso, os empreendimentos de E3 e E5 não oferecem ou apresentam perspectiva de geração de emprego. Para E3: “[...] isso pra mim é um 'bico', quando arranjar um emprego eu vou fechar a empresa. Por isso, não penso em crescer ou colocar outras pessoas pra trabalhar aqui. Até porque mal consigo dinheiro pra mim que dirá pra mais gente, né?”. E E5 diz: "Espero ainda 'tá' costurando muitas peças, do meu jeito e em casa. Quero trabalhar até onde puder, mas só eu mesma. Não sou uma pessoa ambiciosa, sabe? Quero só ajudar minha família”.

No outro extremo, a motivação para empreender por oportunidade está evidente nas falas de E2 e E4. Ao serem perguntados sobre 
a motivação para criar a empresa, os entrevistados responderam que sempre tiveram o sonho de ter seu próprio negócio, como no relato:

Tudo começou por eu ter vontade de ter meu negócio próprio, de ter um espaço pra vender, uma coisa minha, sabe? [...] Bom, mesmo com o emprego de professora e o 'bico' como cabelereira nas horas vagas, a renda era pequena. Então, peguei um dinheiro emprestado com uma pessoa da família, aluguei um ponto comercial, comprei algumas peças de vestuário e uns acessórios e comecei meu sonho (E2, 2015).

Da mesma forma, E4 (2015) relata: "Eh... [pausa para reflexão] o que motivou a gente a abrir o negócio foi a insatisfação com nosso trabalho na época. [...] Fora essa questão, a gente tinha vontade de ter nosso negócio".

Outro aspecto que confirma que E2 e E4 apresentam o perfil do empreendedor por oportunidade é quando falam sobre o trabalho formal. Ambos demonstram, em seus discursos, não terem vontade de voltar ao trabalho formal e à condição de empregado.

Bem... [pausa para reflexão] a loja ainda é pequena se comparada com outras da cidade, mas estou satisfeita com o que ela me proporciona mensalmente. Além de "tá" feliz por realizar meu sonho, "tô" ganhando mais do que no tempo de escola. Por isso, não penso em voltar ao trabalho formal [...] (E2, 2015).

Para E4, a satisfação em ter seu próprio negócio é enorme. Ele acrescenta que "posso conciliar horários, lazer, família e independência financeira" (E4, 2015).

Os empreendedores E2 e E4 empreenderam por meio do reconhecimento de uma oportunidade, pela decisão de seguir em frente e conseguir recursos, pela criação do negócio, pela construção do sucesso e pela coleta de recompensas (BARON E SHANE, 2007). Além disso, 
os entrevistados empreenderam, mesmo possuindo uma alternativa de emprego, movidos pela vontade de independência e para manter ou aumentar a renda (GEM, 2011).

Também é perceptível, nos dois entrevistados, E2 e E4, a análise da ideia e do ambiente, por meio de estratégias, resultando em decisões influenciadas pela razão, para conseguir gerar emprego e renda, como retratado por Lemes Júnior e Pisa (2010) e Castelo Branco e Schneider (2012). A visão de futuro para o negócio também é evidente, ou seja, o empreendedor por oportunidade inicia a empresa sabendo aonde deseja chegar (DORNELAS, 2012).

Contudo, os empreendedores E1 e E6 apresentam características predominantes tanto no empreendedorismo por oportunidade quanto no empreendedorismo por necessidade. Isso porque ambos os entrevistados iniciaram seus negócios pela necessidade de se sustentarem, mas, no decorrer do negócio, inovaram, aproveitaram chances e empreenderam por oportunidade. A falta de vontade em possuir um negócio próprio está presente no discurso de E1 (2015), que relatou: “[...] quero ser empregado e ter tranquilidade do que ter as responsabilidades e problemas de um patrão”. E E6 afirma: “[...] as coisas aconteceram de uma forma muito, como eu posso falar... repentina. Mas por eu ter que pagar meus remédios, minhas despesas, me manter, eu uni o útil ao agradável [...] daí surgiu a oportunidade de trabalhar no centro de artesanato, montar uma lojinha”.

O discurso evidencia que os entrevistados E1 e E6 iniciaram seus negócios por necessidade, ou seja, por precisarem pagar suas contas, se sustentarem. Porém, também há evidências de que os dois entrevistados acabaram empreendendo por aproveitarem uma oportunidade, como é perceptível quando E1 conta que: "Daí, resolvi deixar o ramo de alimentos e vender produtos pra agricultores, ferramentas em geral. Como conhecia muita gente e via a falta de produtos com preço mais em conta e de qualidade, eu resolvi montar meu negócio”. Já E6, 
aproveitou a oportunidade de montar seu negócio no centro de artesanato. $\mathrm{O}$ que demonstra a coragem e a ousadia para arriscar, como é perceptível nesta fala: "Quando sai do emprego e me recuperei do acidente, comecei a bordar e vender umas peças. Foi aí que surgiu a oportunidade de trabalhar no centro de artesanato e não pensei duas vezes. Agarrei a chance e montei minha lojinha”.

Em síntese, por meio das entrevistas, foi possível classificar os empreendedores quanto à motivação para empreender (necessidade ou oportunidade) defendida pelo GEM. O empreendedorismo por necessidade prevaleceu nos entrevistados E3 e E5, que empreenderam por não terem alternativa de renda e emprego formal. Já E2 e E4 empreenderam por oportunidade, ou seja, esses empreendedores tinham o desejo de independência, a vontade de possuir o negócio próprio e aproveitaram oportunidades para empreender. No meio termo, estão E1 e E6, pois ambos começaram a empreender por necessidade, mas, no decorrer do negócio, perceberam alguma oportunidade ou inovaram no produto/serviço ofertado. A classificação dos empreendedores quanto à motivação e suas características até agora explanadas estão resumidas no Quadro 6: 
Quadro 6 - Classificação dos sujeitos de pesquisa quanto à motivação para empreender

\begin{tabular}{|c|c|c|}
\hline Entrevistado & Tipo de empreendedor & Características \\
\hline E1 & $\begin{array}{l}\text { Empreendedor por } \\
\text { necessidade / portunidade }\end{array}$ & $\begin{array}{l}\text {-falta de emprego formal; } \\
\text {-percepção de uma oportunidade; } \\
\text {-coragem e ousadia para arriscar; }\end{array}$ \\
\hline E2 & $\begin{array}{l}\text { Empreendedor por } \\
\text { oportunidade }\end{array}$ & $\begin{array}{l}\text {-possuía um trabalho formal; } \\
\text {-vontade de ter o próprio negócio; } \\
\text {-satisfação com a renda; } \\
\text {-empregado de carteira assinada; }\end{array}$ \\
\hline E3 & $\begin{array}{l}\text { Empreendedor por } \\
\text { necessidade }\end{array}$ & $\begin{array}{l}\text {-falta de emprego formal; } \\
\text {-vontade de ser empregado; }\end{array}$ \\
\hline E4 & $\begin{array}{l}\text { Empreendedor por } \\
\text { oportunidade }\end{array}$ & $\begin{array}{l}\text {-possuía um trabalho formal; } \\
\text {-vontade de ter o próprio negócio; } \\
\text {-satisfação com a renda; } \\
\text {-empregado de carteira assinada; }\end{array}$ \\
\hline E5 & $\begin{array}{l}\text { Empreendedor por } \\
\text { necessidade }\end{array}$ & $\begin{array}{l}\text {-suprir as necessidades familiares; } \\
\text {-falta de qualificação; }\end{array}$ \\
\hline E6 & $\begin{array}{l}\text { Empreendedor } \\
\text { por necessidade / } \\
\text { Oportunidade }\end{array}$ & $\begin{array}{l}\text {-falta de emprego formal; } \\
\text {-percepção de uma oportunidade; } \\
\text {-coragem e ousadia para arriscar. }\end{array}$ \\
\hline
\end{tabular}

Fonte: Elaboração própria (2015).

Para analisar as ações desenvolvidas pelos empreendedores, foram estabelecidos cinco fatores: legalização da empresa, geração de emprego, vontade de crescimento da empresa, inovação e geração de renda.

No fator legalização da empresa, constatou-se que todos os entrevistados estão formalizados na condição de MEI, por estarem cientes de que é uma forma simplificada de empresa, mas com inúmeros benefícios. E1 (2015) explica que aderiu à legalização “[...] Porque 
tanto eu podia comprar meus produtos direto da empresa, com preço mais barato e ainda contribuir pra aposentadoria [...]". Para E2 (2015), com a formalização da empresa, foi possível conseguir “[...] o alvará de funcionamento, pago previdência e agora assinei a carteira de uma funcionária”. Já E4 (2015) enfatiza que reconhece a importância de ter um negócio legalizado para poder comprar seus produtos.

Como a categoria de empresa em estudo é o MEI, forma mais simples de empresa, o empreendedor só tem a possibilidade de registrar um funcionário. Assim, em relação à geração de emprego, apenas E2 e E4 confirmaram ter utilizado esse benefício, como podemos perceber na fala de E2 (2015): “[...] e recentemente assinei a carteira de uma funcionária” e na de E4 (2015): “[...] e assinei a carteira da minha mulher [...]”. Já E6 pretende, em um futuro próximo, contratar um funcionário.

Quanto à vontade de crescimento da empresa, E3 e E5 não demostraram interesse ou empenho para que a empresa pudesse crescer. Como afirma E3 (2015), “[...] a empresa só vai ficar aberta enquanto eu não arranjar um emprego". De forma oposta, os demais entrevistados (E1, E2, E4, e E6), ao falarem de como imaginam sua empresa daqui a cinco anos, demonstraram uma perspectiva de crescimento e desenvolvimento. E1 (2015) pretende “[...] comprar um ponto comercial pra família toda trabalhar comigo". Da mesma forma, E2 (2015) acrescenta que “[...] também quero abrir uma loja, mesmo que menor, em uma cidade aqui vizinha". E de maneira parecida, porém de forma mais estruturada, E4 diz que "pretendo aumentar a empresa, virar uma microempresa, contratar mais um funcionário, abrir outra loja para vender tanto as peças quanto os móveis para a casa”. Já E6 (2015) comenta que “[...] fico imaginando minha lojinha cheia de produtos, uma pessoa me ajudando e também penso em ter outra lojinha no centro".

O quesito inovação foi o mais deficiente, pois apenas E2 destacou formas inovadoras que sua empresa utiliza para conquistar e fidelizar seus clientes: 
Eh...[pausa para pensar] existem muitas lojas na cidade e o produto acaba ficando defasado. Por isso, a gente criou algumas formas de atrair nossas clientes. Por exemplo, temos uma página no facebook, onde a gente toda semana coloca fotos das peças. Também quando chega algo novo, como roupas e acessórios, a gente liga pras clientes mais assíduas. Ah...criamos o cartão felicidade, que funciona assim: depois de um número $x$ de peças, a cliente ganha uma roupa e um acessório da loja. Buscamos fazer sorteios. Isso tudo ajuda a divulgar a loja e chamar mais clientes (E2, 2015).

Por último, a geração de renda proporcionada pela empresa é satisfatória para E2 e E4. O entrevistado E2 (2015) afirma: "Bem a loja ainda é pequena se comparada com outras da cidade, mas estou satisfeita com o que ela me proporciona mensalmente". Igualmente, E4 (2015) relata: “[...] estou satisfeito com o que construímos. Posso conciliar horários, lazer, família e independência financeira”.

Assim, os cinco critérios (legalização da empresa, geração de emprego, vontade de crescimento da empresa, inovação e geração de renda) estabelecidos foram fundamentais para analisar a relação entre a motivação e ação de empreender. Todos os entrevistados estão formalizados na condição de MEI. Já em relação à geração de emprego, apenas E2 e E4 confirmaram ter utilizado esse benefício e E6 disse pretender contratar um funcionário. Quanto à vontade de crescimento da empresa, é notória a falta de interesse apenas de E3 e de E5. No que diz respeito à inovação, há uma grande deficiência, pois esse fator só é utilizado por E2. E a geração de renda, por sua vez, é considerada satisfatória por E2 e E4. A classificação dos empreendedores quanto à motivação e as ações desempenhadas para o desenvolvimento estão resumidas no Quadro 7: 
Quadro 7 - Relação entre a motivação para empreender dos sujeitos de pesquisa e suas ações

\begin{tabular}{|c|l|l|}
\hline Entrevistado & \multicolumn{1}{|c|}{ Motivação } & Ações para o desenvolvimento local \\
\hline E1 & $\begin{array}{l}\text { Necessidade/ } \\
\text { oportunidade }\end{array}$ & $\begin{array}{l}\text {-Não há geração de emprego; } \\
\text {-Satisfação com o negócio; } \\
\text {-Pretensão em expandir o negócio e torná-lo } \\
\text { familiar. }\end{array}$ \\
\hline E2 & Oportunidade & $\begin{array}{l}\text {-Geração de emprego; } \\
\text {-Renda satisfatória; } \\
\text {-Expansão e crescimento do negócio. }\end{array}$ \\
\hline E3 & Necessidade & $\begin{array}{l}\text {-Não há geração de emprego; } \\
\text {-A renda é insatisfatória; } \\
\text {-Não há pretensão em continuar no negócio. }\end{array}$ \\
\hline E4 & Oportunidade & $\begin{array}{l}\text {-Geração de emprego; } \\
\text {-Renda satisfatória; } \\
\text {-Expansão e crescimento do negócio. }\end{array}$ \\
\hline E6 & $\begin{array}{l}\text { Necessidade/ } \\
\text { oportunidade }\end{array}$ & $\begin{array}{l}\text {-Não há geração de emprego; } \\
\text {-Renda satisfatória; } \\
\text {-Pretensão em expandir o negócio. }\end{array}$ \\
\hline
\end{tabular}

Fonte: Elaboração própria (2015).

\subsection{Considerações finais}

Por meio da entrevista com os empreendedores, foi possível classificá-los de acordo com a motivação para empreender, por oportunidade ou por necessidade, apresentada no $\operatorname{GEM}(2010,2011,2013)$. O empreendedorismo por necessidade prevaleceu nos entrevistados E3 e 
E5, que empreendem por falta de um trabalho e renda, na forma de emprego formal. Já E2 e E4 empreendem por oportunidade, ou seja, esses empreendedores gostam de possuir o próprio negócio e buscam reconhecer oportunidades para empreender. No meio termo, estão E1 e E6, pois ambos começaram a empreender por necessidade, mas, atualmente, começam a identificar e explorar oportunidades ou a inovar no produto/serviço ofertado, ainda que de forma incipiente.

Todos os entrevistados estão formalizados na condição de MEI. Os empreendedores motivados pela necessidade, E3 e E5, não são geradores de emprego e a renda não é considerada satisfatória. Essa afirmação deve-se à vontade dos empreendedores de conseguir um trabalho formal, o que também evidencia a falta de interesse em expandir o negócio. Por sua vez, os empreendedores por oportunidade, E2 e E4, possuem um empregado de carteira assinada, o que indica que ambos são geradores de emprego. A renda originada pela empresa é considerada satisfatória pelos empreendedores E2 e E4. No entanto, o fator inovação está presente apenas na empresa de E2, porém isso não anula a vontade desses empreendedores de crescer e expandir o negócio. Na zona de transição entre o empreendedorismo por necessidade e o empreendedorismo por oportunidade, estão os entrevistados E1 e E6. E1 pretende expandir seu negócio, visando ao crescimento da empresa e a uma maior geração de renda e E6 cogita a possibilidade de contratar um funcionário e assim gerar emprego.

Em síntese, os entrevistados por oportunidade, E2 e E4, são geradores de emprego, a renda produzida pela empresa impulsiona o seu crescimento, bem como a busca constante por oportunidades e inovação. De forma diferente, os empreendedores por necessidade, E3 e E5, mantêm o empreendimento apenas para suprir suas necessidades financeiras, gerando renda insuficiente para sustentar a si e a suas famílias e sem perspectiva de gerar emprego e renda para outros. Com base nos resultados encontrados, foi perceptível que eles corroboram 
com o que é defendido pelo GEM $(2010,2011,2012,2013)$; ou seja, que as ações dos empreendedores por oportunidade são mais benéficas e significativas para o desenvolvimento econômico que as daqueles que empreendem por necessidade.

Neste estudo, foi possível constatar que tanto o empreendedorismo movido por necessidade quanto o movido por oportunidade estão presentes nos empreendimentos aracatienses. Ademais, os resultados deste estudo confirmam, ainda que embrionariamente, o que é defendido pelo GEM $(2010,2011,2013)$. Dessa forma, foi possível constatar que os aracatienses que empreendem por oportunidade; em outras palavras, que identificam uma oportunidade de negócio, analisam a ideia, fazem pesquisa de mercado, possuem o desejo de ter o próprio negócio e de independência financeira; contribuem mais para a economia local por gerarem emprego e renda e por terem perspectivas de crescimento. $\mathrm{O}$ que ocorre inversamente com os empreendedores por necessidade, que, por sua vez, empreendem pela falta de opção de trabalho formal, de forma não planejada e sem perspectivas de crescimento.

Vale salientar que esse estudo foi considerado embrionário, devido as suas limitações, em especial no que diz respeito ao número de participantes, bem inferior ao previsto. Ademais, por tratar-se de um estudo de caráter qualitativo, devido a sua natureza, não possibilita a inferência/generalização dessas informações para outro contexto. No entanto, não obstante as suas limitações, contata-se a relevância do empreendedorismo por oportunidade nesse contexto específico, bem como da importância do papel do empreendedor no desenvolvimento econômico e social, pela geração de emprego e renda para o município.

Para estudos futuros, sugere-se ampliar o número de entrevistados para conseguir um maior aprofundamento da análise. Como sugestão, também seria interessante utilizar uma amostra de empreendedores classificados com um porte de faturamento maior, como, por exemplo, os microempresários (MEs), ou até mesmo fazer um comparativo de 
acordo com o setor/atividade de cada empreendedor. Ou ainda analisar a relação da motivação para empreender com aspectos pessoais como idade, sexo e grau de instrução. Por fim, outra sugestão é a replicação deste estudo com uma abordagem quantitativa. 


\section{REFERÊNCIAS}

ARACATINET. Tudo sobre o Aracati na net. 2009. Disponível em: http: <//www.aracati.net.> Acesso em: 07 jan. 2015.

BARDIN, L. Análise de conteúdo. Lisboa: Edições 70, 1979.

BARON, R. A.; SHANE, S. A. Empreendedorismo: uma visão de processo. São Paulo: Thomson Learning, 2007.

CASTELO BRANCO, H. J.; SCHNEIDER, E. I. A caminhada empreendedora: a jornada de transformação de sonhos em realidade. Curitiba: InterSaberes, 2012.

DEGEN, R. J. Empreendedorismo: uma filosofia para o desenvolvimento sustentável e a redução da pobreza. RCA Revista de Ciências da Administração, v. 10, n. 21, p. 11-30, 2008. Quadrimestral. Disponível em: <http://dx.doi.org/10.5007/21758069.2008v10n21p11>. Acesso em: $12 \mathrm{dez} .2014$.

DEGEN, R. J. O empreendedor: empreender como opção de carreira. São Paulo: Pearson Prentice Hall, 2009.

DOLABELA, F. Oficina do empreendedor. São Paulo: Cultura, 1999.

DORNELAS, J. C. A. Empreendedorismo corporativo: como ser empreendedor, inovar e se diferenciarem organizações estabelecidas. Rio de Janeiro: Elsevier, 2001.

DORNELAS, J. C. A. Empreendedorismo: transformando ideias em negócios. Rio de Janeiro: Elsevier, 2012.

DRUCKER, P. F. Inovação e espírito empreendedor: prática e princípios. São Paulo: Thomson, 2005. 
FILION, L. J. Empreendedorismo: empreendedores e proprietáriosgerentes de pequenos negócios. Revista de Administração, v. 34, n. 2, p. 5-28, 1999.

GLOBAL ENTREPRENEURSHIP MONITOR (GEM).

Empreendedorismo no Brasil. Curitiba: IBQP, 2010.

GLOBAL ENTREPRENEURSHIP MONITOR (GEM).

Empreendedorismo no Brasil. Curitiba: IBQP, 2011.

GLOBAL ENTREPRENEURSHIP MONITOR (GEM).

Empreendedorismo no Brasil. Curitiba: IBQP, 2013.

GLOBAL ENTREPRENEURSHIP MONITOR (GEM).

Empreendedorismo no Brasil. Curitiba: IBQP, 2015.

INSTITUTO BRASILEIRO DE GEOIGRAFIA E ESTATÍSTICA (IBGE) CIDADES. População da cidade de Aracati em 2014. 2014. Disponível em: $<$ http://www.cidades.ibge.gov.br $>$. Acesso em: 07 jan. 2015.

LEMES JÚNIOR, A. B.; PISA, B. J. Administrando micro e pequenas empresas. Rio de Janeiro: Elsevier, 2010.

MENDES, J. Manual do empreendedor: como construir um empreendimento de sucesso. São Paulo: Atlas, 2009.

MINAYO, M. C. de S. O desafio do conhecimento: pesquisa qualitativa em saúde. 4. ed. São Paulo, 1996.

SARFATI, G. Estágios de desenvolvimento econômico e políticas públicas de empreendedorismo e de micro, pequenas e médias empresas (MPMEs) em perspectiva comparada: os casos do Brasil, do Canadá, do Chile, da Irlanda e da Itália. RAP -

Revista de Administração Pública, v. 47, n. 1, p. 25-48, 2013.

Disponível em: $<$ http://www.scielo.br/scielo.php?pid=S0034$76122013000100002 \&$ script=sci_arttext $>$. Acesso em: 23 maio 2015. 
SCHUMPETER, J. A teoria do desenvolvimento econômico. São Paulo: Abril Cultural, 1983. 


\section{APÊNDICE - ROTEIRO DE ENTREVISTA}

Sexo:

Idade:

Nível de escolaridade:

Atividade desenvolvida pela empresa:

1. O que motivou a criação da empresa?

2. Você foi induzido a empreender por alguém (família, amigos, instituições)?

3. Por que decidiu legalizar sua empresa?

4. Trabalhava em algum lugar quando decidiu iniciar seu negócio? E atualmente, trabalha em algum lugar além de seu negócio?

5. Você tem a intenção/vontade de retornar ao mercado de trabalho formal como um empregado?

6. Se você estivesse como empregado em uma empresa, acredita que estaria ganhando mais do que como dono da sua própria empresa?

7. Você realizou alguma pesquisa de mercado, analisou ideias de negócio ou fez um planejamento antes de iniciar sua empresa?

8. Você considera que tem competência necessária para gerenciar seu negócio?

9. Busca participar de cursos que o ajudem nesse gerenciamento do negócio?

10. Você se considera um ser empreendedor? Por quê?

11. Você considera que os produtos/serviços que oferece são inovadores? Por quê?

12. Você está atento às oportunidades do mercado ou procura não dar importância para elas? 
13. Ao identificar uma oportunidade de negócio (seja no sentido de ofertar um novo produto/serviço ou de expandir a empresa), você arrisca, mesmo sabendo das incertezas dessa decisão ou não busca correr riscos, deixa a chance passar?

14. Daqui a cinco anos, como você imagina que sua empresa esteja no mercado? 